\title{
An index for quantifying female education and child health in emerging economies
}

\author{
José Antonio Rodríguez Martín, ${ }^{1}$ María del Mar Holgado Molina, ${ }^{2}$ \\ José Antonio Salinas Fernández ${ }^{2}$
}

${ }^{1}$ Department of Applied Economics, University of Granada, Granada, Spain ${ }^{2}$ Department of Spanish and International Economics, University of Granada, Granada, Spain

\section{Correspondence to} Dr José Antonio Rodríguez Martín, Campus de Cartuja s/ n, University of Granada, Granada 18071, Spain; josearm@ugr.es

Received 27 June 2014 Revised 11 October 2014 Accepted 13 October 2014

\section{CrossMark}

\section{To cite: Rodríguez}

Martín JA, Holgado

Molina M del M, Salinas

Fernández J A. Arch Dis

Child 2015;100(Suppl 1):

s10-s12.

\begin{abstract}
Objective To construct an index to measure female education and child health in the least developed countries (LDCs) of Asia.

Methods and results The design of our index includes the variables of female education and child health defined in the goals of the Millennium Declaration. For this purpose, we used Pena's $P_{2}$ distance method for 2011, the last year for which data were available for the set of variables.

Conclusion We have proposed a territorial measure and classification of female education and child health in the LDCs of Asia. We believe that the most striking differences between countries relate to basic female education variables such as girls' primary completion rate, and female literacy.
\end{abstract}

\section{INTRODUCTION}

In 2000, the Millennium Declaration was signed at the United Nations General Assembly in New York. This document enshrined the Millennium Development Goals (MDGs) as the international community's collective commitment to create a better tomorrow for billions of people, prioritising efforts to reduce poverty and hunger; empower women; increase access to essential services like education, healthcare, clean water, and sanitation; and forge strong global partnerships for development. ${ }^{1}$

Reducing the number of children who die before the age of 5 years is the fourth MDG (MDG 4). Reaching the MDG on reducing child mortality will require universal coverage with key effective, affordable interventions. ${ }^{2}$ At the same time, systematic action is required to target the main causes of child death and the most vulnerable children.

This includes a stronger focus on neonatal mortality, which is now a driving factor in child mortality overall. Simple, cost-effective interventions such as postnatal home visits have proven effective in saving newborn lives. Emerging evidence has shown alarming disparities in under-5 mortality within countries, and these inequities must be addressed. Children born into the poorest households are almost twice as likely to die before age 5 as their wealthiest counterparts. Poverty is not the only divider, however. Children are also at greater risk of dying before age 5 if they are born in rural areas or to a mother denied basic education. ${ }^{1}$

Further education also allows mothers access to more information on the prevention of widespread diseases such as malaria and AIDS in these areas, and in general, would permit the countries to achieve better standards of child health. ${ }^{3}$

\section{What is already known on this topic}

The improvements in child survival are seen at the very beginning of female education, whatever the initial conditions-socioeconomic, cultural, public services - and however unsatisfactory the nature of the schooling experience. A variety of datasets find a uniformly linear inverse relationship, with the risk of under- 5 mortality falling by $2-5 \%$ for every additional year of maternal schooling.

\section{What this study adds}

We believe that the most striking differences between countries relate to basic female education variables such as girls' primary completion rate, and female literacy.

The improvements in child survival are seen at the very beginning of female education, whatever the initial conditions-socioeconomic, cultural, public services-and however unsatisfactory the nature of the schooling experience. ${ }^{4} \mathrm{~A}$ variety of datasets find a uniformly linear inverse relationship, with the risk of under-5 mortality falling by $2-5 \%$ for every additional year of maternal schooling. ${ }^{5}$

Education and health are strongly related. The substantial increase in education, especially of women, and the reduction of the gender gap have important implications, not only for health but also for the status and roles of women in society. The continued increase in educational attainment, even in some of the poorest countries, suggests that rapid progress in terms of MDG 4 might be possible. $^{6}$

Thirty years of research on data collected throughout Africa, Asia and Latin America have confirmed the original findings ${ }^{7}$ that women's schooling was robustly associated with, and a possible determinant of, child mortality reduction in the less developed countries (LDCs) during the second half of the 20th century. The evidence shows definitively that a mother's schooling-at high and low levels of education, in cities and villages, under diverse economic conditions-is related to the chances of her child's survival. ${ }^{8}$ The more we learn about maternal literacy, the more it looks like an indispensable passport to life-saving services for mothers and children. 
For the LDCs, the women's path to development is the best path. Emphasis on the problems, concerns, and capacities of women is the bright hope of the development future. ${ }^{9}$ With increased literacy, women will be able to influence the economic, social and human aspects of their community. Education 'can enhance a society's ability to overcome poverty, increase incomes, and improve health and nutrition'. ${ }^{10}$ Education allows women to make informed choices and seek proper health care. A WHO report on Asia and the Pacific shows that female literacy rates are a strong predictor of maternal mortality rates; the more literate the female population, the lower the maternal mortality rate. ${ }^{11}$

A factor that holds significant promise for improving child health levels is parental education in emerging economies. ${ }^{12}$ Indeed, it has even been argued that parental education has contributed more to mortality decline than the provision of health services, ${ }^{13}$ and even small levels of education improve child survival. ${ }^{14}$

In the Cote d'Ivoire, it has been found that mother's schooling has a positive effect on child weight and height. ${ }^{15}$ In Indonesia, maternal schooling contributes to child micronutrient status directly, but also through its effects on nutrition knowledge and household expenditures. ${ }^{16}$

In this regard, evidence from 22 developing countries ${ }^{17}$ shows that there is a strong correlation between maternal education and markers of child health: infant mortality, children's height-for-age, and immunisation status. In three African countries, children with mothers whose education level was beyond primary school were less likely to be malaria-positive, with a significant relationship between maternal education and childhood malaria infection. ${ }^{18}$ Particularly in Kenya, overall, children born to mothers with only a primary education were 2.17 times more likely to be fully immunised than those whose mothers lacked any formal education. ${ }^{19}$

In this study we develop a synthetic indicator known as the $\mathrm{P}_{2}$ distance method, ${ }^{20-26}$ to measure fulfilment of the MDGs in female education and child health in the LDCs of Asia, and to analyse the disparities present in 2011, taking the MDGs as the reference, in the framework of the ongoing discussions on the post-2015 MDGs. The LDCs of Asia are considered to be in need of the highest degree of attention on the part of the international community. ${ }^{27}$

This indicator permits comparisons to be made for countries in 2011 using as a baseline reference the information contained in a set of social indicators by virtue of the detailed statistical information contained in the report on the MDGs, ${ }^{1}$ which provide a more extensive and more reliable set of statistics on MDGs 1, 2, 3, 4 and 6 in Asia.

These statistics are jointly compiled from the work of the Inter-Agency and Expert Group (IAEG) on MDG indicators, coordinated by the United Nations Statistics Division. The year of analysis is 2011, but for those variables where information was not available for that date, the nearest year was taken as an alternative.

\section{COUNTRY CLASSIFICATION}

The results show that the country with the best female education and child health in 2011 was the Maldives. The Maldives was followed by Myanmar and Bhutan, with high relative values of these countries in most of the variables analysed of MDGs, above the average distance.

In contrast, Afghanistan, Yemen and East Timor were among the countries with the worst theoretical situations of female education and child health. In this regard, given the low relative values of these countries in most of the MDG variables analysed, their position is not surprising.

This means that the maximum inter-country distance, between the maximum and minimum value obtained, which shows that the disparities of female education and child health in the LDCs of Asia surveyed, were high in 2011.

\section{ORDERING OF THE PARTIAL INDICATORS}

Finally, the correction factor of the partial indicators, that is, the relative importance of each variable in the final indicator of female education and child health in the LDCs of Asia, has been estimated. The first variable in order of entry is 'Gender Parity Index in primary level enrolment', meaning that it contributes $100 \%$ of useful and non-redundant information for calculating the $\mathrm{DP}_{2}$ synthetic indicator. ${ }^{28} 29$

The next variable in order of entry is 'Gender Parity Index in tertiary level enrolment'. We can see that 'primary completion rate, girls' is in position 3, and 'literacy rates of 15-24 years old, women, percentage' is in position 4, so these four variables associated with the MDGs of women's education present a high relative importance in the explanation of female education and child health of the countries studied.

\section{CONCLUSIONS}

The index of female education and child health was constructed using a large number of variables defined in the MDGs of the United Nations. It is clear that much more needs to be done for MDGs to be achieved by $2015 .^{30}$ The aim is to further cut child mortality by 2015 by two thirds from the 1990 level.

The evidence shows definitively that a mother's schooling - at high and low levels of education, in cities and villages, under diverse economic conditions-is related to the chances of her child's survival. ${ }^{8}$ The more we learn about maternal literacy, the more it looks like an indispensable passport to life-saving services for mothers and children.

Pena's $\mathrm{DP}_{2}$ distance method shows the existence of territorial disparities in female education and child health in the LDCs of Asia in 2011, according to the values of the variables studied, indicating that these countries present certain differences with regard to attainment of the MDGs. This is a quantitative synthetic indicator, which includes the characteristic of multidimensionality to allow comparisons among the LDCs of Asia.

Specifically, the values of the synthetic indicator show a considerable gap between the maximum and minimum value obtained by the best- and worst-ranked countries in 2011: respectively, the Maldives and Myanmar on the one hand, and Yemen and Afghanistan on the other. The rest of the countries are between these extremes.

The variables included in MDG 2 ('achieve universal primary education') and MDG 3 ('promote gender equality and empower women'), seem to show the highest correlation with female education and child health in the LDCs of Asia in 2011. These goals can be considered very important for driving the child health of these countries in the coming years, in the framework of the aid strategies of international organisations whose aim is to reduce territorial disparities in female education and child health in the LDCs of Asia.

Finally, universal literacy, especially among women, decreases child and maternal health risks. ${ }^{31-33}$ Although some encouraging advances have been made in female education in the LDCs of Asia, especially those occupying the top positions in our classification, faster progress is required to achieve MDGs 2 and 3 in the coming years, which without doubt would result in better overall child health in the LDCs. 
Funding JARM gratefully acknowledges the financial support provided by the Spanish Agency of Science and Technology (Individual characteristics, preferences and welfare. Reference: ECO2013-44879-R).

Competing interests None.

Patient consent Obtained.

Provenance and peer review Commissioned; internally peer reviewed.

\section{REFERENCES}

1 United Nation. The millennium development goals report. New York: Oxford University Press, 2013.

2 Rodríguez JA. Index of child health in Africa. In Michalos AC, ed. Encyclopedia of quality of life and well-being research. New York: Springer, 2014:3.155-60.

3 Rodríguez JA, Moreno MD, Sánchez J. An index of education and child health in the Horn of Africa. Qual Quant 2014;48:863-70.

4 Basu AM, Stephenson R. Low levels of maternal education and the proximate determinants of childhood mortality: a little learning is not a dangerous thing. Soc Sci Med 2005;60:2011-23.

5 Cleland J, Kaufmann G. Education, fertility and child survival: unravelling the links. In Basu AM, Aaby P, eds. The methods and uses of anthropological demography. Oxford: Clarendon Press, 1998:128-52.

6 Gakidou E, Cowling K, Lozano R, et al. Increased educational attainment and its effect on child mortality in 175 countries between 1970 and 2009: a systematic analysis. Lancet 2010;376:959-74.

7 Caldwell JC. Education as a factor in mortality decline: an examination of Nigerian data. Popul Stud 1979;33:395-413.

8 LeVine RA, Rowe ML. Maternal literacy and child health in less-developed countries: evidence, processes, and limitations. J Dev Behav Pediatr 2009;30:340-9.

9 Reagan M. UN Decade for Women Conference Held in Nairobi. Department of State Bulletin, 1986. February: 89-92.

10 United Nation. Closing the gender gap. UN chronicle. New York: Oxford University Press, 1990.

11 World Health Organization (WHO). Health in Asia and the Pacific. Switzerland: World Health Organization-Western Pacific \& South-East Asia, 2008.

12 Aslam M, Kingdon GG. Parental education and child health-understanding the pathways of impact in Pakistan. World Dev 2010;40:2014-32.

13 Sandiford P, Cassel J, Montenegro M, et al. The impact of women's literacy on child health and its interaction with access to health services. Pop Stud 1995;49:5-17.

14 Mensch B, Lentzner H, Preston SH. Socioeconomic differentials in child mortality in developing countries. New York: Department of International Economic and Social Affairs, 1985.
15 Strauss J. Households, communities, and preschool children's nutrition outcomes: evidence from rural Côte d'Ivoire. Econ Dev Cul Change 1990;38:231-49.

16 Block AS. Maternal nutrition knowledge versus schooling as determinants of child micronutrient status. Oxford Econ Pap 2007;59:330-53.

17 Desai S, Alva S. Maternal education and child health: Is there a strong causal relationship? Demogr 1998;35:71-81.

18 Njau JD, Stephenson R, Menon MP, et al. Investigating the important correlates of maternal education and childhood malaria infections. Am J Trop Med Hyg 2014;91:509-19.

19 Abuya BA, Onsomu EO, Kimani JK, et al. Influence of maternal education on child immunization and stunting in Kenya. Matern Child Health J 2011;15:1389-99.

20 Pena JB. Problemas de medición del bienestar y conceptos afines. Madrid: Instituto Nacional de Estadística (INE), 1977.

21 Zarzosa P. Aproximación a la medición del Bienestar Social. Valladolid: Secretariado de Publicaciones, 1996.

22 Somarriba N, Pena B. Synthetic indicators of quality of life in Europe. Soc Indic Res 2009;96:115-33.

23 Cuenca E, Rodríguez JA. Medición de las disparidades entre indicadores asociados al bienestar social en los Países Menos Adelantados (PMA) de Asia. Rev de Econ Mund 2010;25:83-108.

24 Rodríguez JA. An index of child health in the least developed countries (LDCs) of Africa. Soc Indic Res 2011;105:309-22.

25 Rodríguez JA, Salinas JA, Ubiña AJ. An index of progress towards the MDG 6 in sub-saharan Africa: combat HIV, AIDS and Malaria. Child Indic Res 2012;5:199-213.

26 Zarzosa P, Somarriba N. An assessment of social welfare in Spain: territorial analysis using a synthetic welfare indicator. Soc Indic Res 2013;111:1-23.

27 United Nation. Programme of action for the least developed countries. New York: Oxford University Press, 2001.

28 Pena JB. La medición del bienestar social: una revisión crítica. Est Econ Apli 2009;2:3299-3.324.

29 Rodríguez JA, Holgado M, Salinas JA. An assessment of millennium development goal (Mdg) 3 in least developed countries of Asia. Appl Res Qual Life 2014;doi: 10. 1007/s11482-013-9298-7.

30 United Nation. Beyond the midpoint: achieving the millennium development goals. New York: Oxford University Press, 2010.

31 UNICEF. Child poverty in perspective: an overview of child well-being in rich countries. Innocenti report card 7. Florence: UNICEF, 2007.

32 Rodríguez JA, Salinas JA. An index of maternal and child health in the least developed countries of Asia. Gac Sanit 2011;26:190-2.

33 United Nation. Children's fund: progress in child-wellbeing: building on what works. New York: UNICEF, 2012. 